\title{
Treatment of perioperative swelling
} by rest, ice, compression, and elevation (RICE) without and with additional application of negative pressure $\left(\mathrm{RICE}^{+}\right)$in patients with a unilateral ankle fracture: study protocol for a monocentric, evaluator-blinded randomized controlled pilot trial

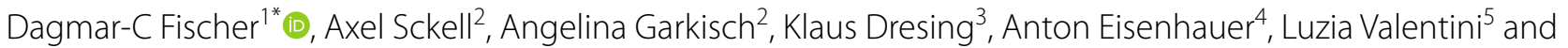
Thomas Mittlmeier ${ }^{2}$

\begin{abstract}
Background: Edema is commonly seen after surgical fixation of ankle fractures. Rest, ice, compression, and elevation (RICE) is an established combination to prevent swelling but hardly able to stimulate lymphatic resorption. Recently, an epicutaneously applied negative pressure suction apparatus (LymphaTouch ${ }^{\circledR}$ ) has been introduced to stimulate lymphatic flow. While postoperative recovery, soft tissue, and osseous healing as well as functional outcome are probably linked to the amount of postoperative swelling, estimates on this relative to prevention (RICE) or prevention + stimulated resorption (RICE ${ }^{+}$) of fluid are scarce.

Methods and analysis: This is a single-center, evaluator-blinded randomized pilot trial to investigate postoperative swelling in adults requiring surgical fixation of a closed unilateral ankle fracture. A total of 50 patients will be recruited and randomly assigned to RICE or RICE ${ }^{+}$prior to surgery. All patients will undergo evaluator-blinded measurements of the ankle volume the day before surgery and subsequently from the evening of the $2 \mathrm{nd}$ postoperative day every $24 \mathrm{~h}$ until discharge. RICE will be initiated right after surgery and continued until discharge from the hospital in all patients. Additional application of negative pressure therapy $\left(\mathrm{RICE}^{+}\right)$will be initiated on the morning of the 2nd postoperative day and repeated every $24 \mathrm{~h}$ until the time of discharge from the hospital. Outcome measures are (i) the relative amount and the time course of the postoperative swelling, (ii) the demand for analgesic therapy (type and amount) together with the perception of pain, (iii) the rate of complications, and (iv) mobility of the ankle joint and the recovery of walking abilities during a 12-weeks follow-up period. Serum and urine samples taken prior to sugery and
\end{abstract}

*Correspondence: dagmar-christiane.fischer@med.uni-rostock.de

1 Department of Pediatrics, Rostock University Medical Center, Ernst-Heydemann-Str. 8, 18057 Rostock, Germany

Full list of author information is available at the end of the article

(c) The Author(s) 2021. Open Access This article is licensed under a Creative Commons Attribution 4.0 International License, which permits use, sharing, adaptation, distribution and reproduction in any medium or format, as long as you give appropriate credit to the original author(s) and the source, provide a link to the Creative Commons licence, and indicate if changes were made. The images or other third party material in this article are included in the article's Creative Commons licence, unless indicated otherwise in a credit line to the material. If material is not included in the article's Creative Commons licence and your intended use is not permitted by statutory regulation or exceeds the permitted use, you will need to obtain permission directly from the copyright holder. To view a copy of this licence, visit http://creativecommons.org/licenses/by/4.0/. The Creative Commons Public Domain Dedication waiver (http://creativeco mmons.org/publicdomain/zero/1.0/) applies to the data made available in this article, unless otherwise stated in a credit line to the data. 
during postoperative recovery will allow to evaluate the ratio of naturally occurring stable calcium isotopes $\left(\delta^{44 / 42} \mathrm{Ca}\right)$ as a marker of skeletal calcium accrual.

Ethics and dissemination: The protocol was approved by the institutional Ethics Committee (Rostock University Medical Center, Rostock, Germany) in accordance with the Declaration of Helsinki (approval number: A 2020-0092). The results of this study will be actively disseminated through scientific publications and conference presentations.

Trial registration: DRKS, DRKS00023739. Registered on 14 December 2020

Keywords: Ankle fracture, Rest, Ice, Compression, Elevation, Edema, Postoperative swelling, Negative pressure therapy, Soft tissue, Osseous healing, Complications

\section{Introduction}

\section{Background and rationale}

Ankle fractures account for approximately $9 \%$ of all fractures, and occur preferentially either in physically active adults or as an osteoporotic fracture in the elderly [1-4]. Any injury, either accidentally as with the fracture or, in addition, as with surgical fixation, causes the release of inflammatory mediators with concomitant extravasation of fluid, i.e., swelling which in turn induces pain and hampers mobility. Preoperative relief of the edema is required for tension-free wound closure while postoperative swelling bears the inherent risk of wound complications and infections. Thus, although resolving pre- and postoperative swelling is ultimately required, the well-established and widely used combination of rest, ice, compression, and elevation (RICE) prevents the formation of edema rather than stimulating lymphatic resorption. Manual lymphatic drainage is a well-introduced procedure for managing post-lymphadenectomy lymphedema via stimulating of lymph circulation [5, 6]. However, clinical studies on lymphatic treatments after orthopedic surgery of the lower extremities are rare, and the results are controversial. Moreover, protocols differ with respect to inclusion/exclusion criteria, outcome measures, treatment modalities, and timing [6-12].

Very recently, an epicutaneously applied negative pressure suction apparatus $\left(\right.$ LymphaTouch $^{\circledR}$, Helsinki, Finland) has been introduced and successfully been used for the reduction of pre- and postoperative swelling in patients undergoing unilateral surgery on the upper and lower extremity $[8,13]$. It is appealing to fortify the classical RICE concept by additional stimulation of lymphatic flow $\left(\mathrm{RICE}^{+}\right)$after surgical fixation of a closed unilateral ankle fracture. We already established contact-less photooptical 3D-scanning as a reliable and highly standardized method for the determination of ankle volume [14]. Additional measures of short- and long-term outcome relative to postoperative care according to the RICE or $\mathrm{RICE}^{+}$concept are pain, postoperative complications, mobility of the joint, and walking abilities. Quantitative pulse echography (Bindex ${ }^{\circledR}$, Bone Index Finland Ltd., Kuopio, Finland) will allow for scoring of bone mineral density (normal, osteopenic or osteoporotic). The ratio of naturally occurring stable calcium isotopes $\left(\delta^{44 / 42} \mathrm{Ca}\right)$ in the serum and urine has been introduced as a marker of bone mineral balance $[15,16]$. Thus far, this marker is preferentially used to monitor bone mineral loss rather than accrual. Like numerous other blood-born marker, serum calcium concentration depends on the time of blood sampling, i.e., samples taken before and after breakfast are likely to contain different amounts of calcium. Thus, standardized blood sampling is a major prerequisite to use calcium isotope measurement as a marker of skeletal health. Since standardized blood sampling in an out-patient setting is challenging, we decided to incorporate this as a small side project. Patients are fairly comparable with respect to the skeletal defect (unilateral ankle fracture), and blood sampling before breakfast is easily done in a hospital setting. Blood and urine samples will be taken on a voluntary base and we expect that $\delta^{44 / 42} \mathrm{Ca}$ will change according to the recruitment of calcium into the bone, i.e., allows to monitor the process of fracture healing during postoperative recovery and the follow-up period relative to baseline values prior to surgery.

\section{Methods/design \\ Aim of the study}

This monocentric, evaluator-blinded randomized controlled pilot-trial aims (i) to obtain an estimate on the standard deviation of the normalized ankle volume during postoperative recovery and (ii) to assess the feasibility of the proposed randomized allocation to the treatments and the suggested outcome measures. The latter include the demand for analgesics, the perception of pain, the rate of complications, the mobility of the joint, walking abilities, and skeletal calcium accrual together with bone mineral density. In summary, the results may broaden the knowledge on the interference between soft tissue swelling, functional outcome, and bone metabolism.

\section{Design and setting of the study}

This is a single-center evaluator-blinded randomized controlled pilot trial with two parallel groups and a 1:1 
allocation ratio of patients receiving surgical fixation of an unilateral ankle fracture. The study is going to be conducted at the Department of Traumatology, Hand and Reconstructive Surgery at Rostock University Medical Center. Starting from the 2nd postoperative day, there will be daily interventions for up to 10 days (i.e., the time of hospitalization). Repeated measures of outcome will be performed at baseline (prior to surgery), during the intervention period, and during the 12-week follow-up period. The study will be performed according to the ethical standards of the Institutional Ethics Committee (approval number: A 2020-0092) and in accordance with the Declaration of Helsinki.

\section{Participants, interventions, and outcomes Eligibility criteria}

Adults ( $\geq 18$ years of age) requiring surgical fixation of a closed unilateral ankle fracture (any fracture type scheduled for surgery) are eligible. Additional inclusion criteria are (i) a BMI of at least $16 \mathrm{~kg} / \mathrm{m}^{2}$ and at a maximum $35 \mathrm{~kg} / \mathrm{m}^{2}$, (ii) willingness to be randomized, and (iii) the ability to give written informed consent. Patients with open uni- or bilateral fractures, a history of secondary lymphedema due to tumoral disease during the preceding 5 years, dietary patterns other than omnivore or lacto-ovo-vegetarian (e.g., vegan, macrobiotic), and/or being incapable of adherence to follow-up examinations are excluded. Furthermore, pregnant women are not eligible. Eligible patients will receive detailed information on the study by trained physicians of our outpatient facility where preoperative assessment and preoperative necessary preparations for the surgical procedure take place when the indication for surgery has been secured. Prior to enrollment, all patients have to read and to sign the informed consent.

\section{Randomization}

A researcher neither involved in clinical care or the dayto-day running of the trial will handle the randomization. Patients who gave written informed consent are assigned to either one of the treatment arms according to the results of a list-based block randomization procedure [17]. Only the person in charge to apply the device-based negative pressure therapy and the patient are informed on the assigned treatment, and both are instructed not to comment on the mode of therapy.

\section{Sample size justification}

This pilot study is designed to obtain an estimate on the standard deviation of the normalized ankle volume during postoperative recovery and to assess the feasibility of both, the proposed randomized allocation to the treatment arms, and the suggested outcome measures.
According to the recommended sample size for feasibility studies, we aim to enroll 25 participants per arm (50 patients in total) [18-21]. This number should be sufficient to allow the determination of variability.

\section{Intervention}

Patients randomized to either treatment group will receive identical postoperative care, i.e., prescription of analgesics and the classical RICE concept to stimulate resorption of the postoperative swelling. The latter will be initiated right after surgery and continued until discharge from the hospital. Patients are advised to strictly adhere to the RICE concept in order to minimize variability inherent to this type of therapy. In particular, a positioning splint will be placed under the knee and the operated lower leg to elevate the ankle above heart level and ice packs will be provided for cooling during daytime according to the individual preference of the patient. The staff on the ward will not be notified on the treatment arm but asked to record the number of ice packs per day as a surrogate measure of both, the individual preference for cooling and adherence to the baseline therapy. Mobilization during the postoperative period and walking will be allowed with crutches and a lower leg orthosis under partial weight-bearing with $20 \mathrm{~kg}$ according to a personal training on a scale under supervision of a physiotherapist and without notification of the physiotherapist on the treatment arm. In patients allocated to $\mathrm{RICE}^{+}$, the device-based negative pressure therapy will be initiated on the morning of the 2nd postoperative day by a trained physician/medical student (last year of education) and repeated every $24 \mathrm{~h}$ until discharge from the hospital. The first treatment will be right after the wound dressing has been changed to a transparent and sterile film dressing (OPSITE ${ }^{\circledR}$ Post-OP visible, Smith \& Nephew Woundcare, Hamburg, Germany). This wound dressing will be applied to all study patients and allow for constant monitoring of the wound and peri-wound area while eliminating the need to remove the dressing every time before the objective evaluation of the edema by $3 \mathrm{D}$ scanning and to ensure blinding of the staff with respect to the treatment arm. In all patients scheduled for $\mathrm{RICE}^{+}$, negative pressure therapy ( $30 \mathrm{~min}$ per session) will be applied by a trained physician/medical student in a standardized manner, i.e., starting at the supraclavicular fossa and following the lymphatic vessels down to the affected ankle. We use the same sequence as in manual lymphatic drainage, i.e., to increase lymph kinetic in normal lymphatics by mild mechanical stimuli as this augments the drainage across the lymphatic watershed. When starting manual lymphatic treatment at the inflow of the lymph into the venous system, edema fluid will pass through the already dilated area with successive decongestion of the 
lymphatic trunk $[13,22,23]$. The size of the treatment cup (60-80 $\mathrm{mm}$ diameter), the pressure $(20-250 \mathrm{mmHg})$, and the frequency of vibration $(20-90 \mathrm{~Hz})$ will be adapted to individual needs (Table 1). To ensure blinding of all persons involved in postoperative care, the person in charge for the device-based negative pressure therapy will show up with the equipment at the pre-defined time anyway.

Patients of either treatment arm will be instructed not to comment on the mode of physical therapy, and the evaluator will have access neither to the ward during the times of treatment nor to the randomization list.

\section{Outcome measures}

All measures will be taken at baseline and at pre-specified time points during the treatment and follow-up period (Fig. 1 and Table 2). Non-contact 3D scanning will be used to quantify postoperative swelling relative to the healthy/unaffected ankle by an evaluator blinded for the treatment. Scanning will start on the evening of the 2nd postoperative day. Subsequent measurements will be taken every $24 \mathrm{~h}$ until discharge from the hospital and by the same blinded evaluator. This data will allow to determine the variability of the normalized ankle volume and the kinetic of edema reduction (primary outcome).
Secondary outcome measurements consist of the daily recordings of the individual pain perception by means of numeric analog scale, of the type and amount of analgesics, the quantification of the range of motion at both ankles (dorsi- and plantarflexion) with a goniometer at the time of discharge from the hospital and during follow-up visits. Walking abilities (factors of imbalance, ground reaction force) at the time of discharge from the hospital and during the follow-up period will highlight the functional outcome. Bone mineral density will be determined by means of quantitative pulse echography (Bindex ${ }^{\circledR}$, Bone Index Finland Ltd., Kuopio, Finland) [24] at the time points indicated (Table 2). Sampling of blood and urine is on a voluntary base only, and these samples will be used to investigate the ratio of naturally occurring stable calcium isotopes $\left(\delta^{44 / 42} \mathrm{Ca}\right)$ in the serum and urine as a marker of bone mineral balance during fracture healing.

\section{Monitoring of the ankle volume during postoperative recovery in the hospital}

The primary objective of the study is to investigate the amount of postoperative swelling relative to the application of RICE or RICE ${ }^{+}$. To ensure objective evaluation, a contact-less $3 \mathrm{D}$ optical scanning procedure $\left(\operatorname{Artec}^{\circledR} \mathrm{eva}\right.$,

Table 1 Device-based application of negative pressure during postoperative recovery

\begin{tabular}{|c|c|c|c|c|c|}
\hline Treatment area & Technique & $\begin{array}{l}\text { Negative } \\
\text { pressure } \\
{[\mathrm{mmHg}]}\end{array}$ & Work-to-rest ratio & Details & Duration \\
\hline Supraclavicular fossa region (both sides) & Stationary & $50-80$ & $2.0 s / 50 \%$ & $\begin{array}{l}\text { Bilateral treatment } 3 \text { pulsations on } 5 \text { spots/ } \\
\text { side }\end{array}$ & $1 \mathrm{~min}$ \\
\hline Inguinal area of the injured side & Stationary & $50-100$ & $2.0 s / 50 \%$ & $\begin{array}{l}\text { 3-5 pulsation on the same spot followed by } \\
\text { movement to the next spot }\end{array}$ & $1 \mathrm{~min}$ \\
\hline \multirow[t]{2}{*}{ Thigh circumferential } & Stationary & $50-150$ & $2.0 s / 50 \%$ & $\begin{array}{l}\text { 1. Step: } 3-5 \text { pulsation on the same spot fol- } \\
\text { lowed by movement to the next spot }\end{array}$ & $4 \min$ \\
\hline & Sliding & $50-150$ & $2.0 \mathrm{~s} / 50 \%$ & $\begin{array}{l}\text { 2. Step: direction distal to proximal towards } \\
\text { the inguinal lymph nodes }\end{array}$ & $2 \min$ \\
\hline Knee anterior + posterior & Stationary & $50-150$ & $2.0 s / 50 \%$ & $\begin{array}{l}\text { 3-5 pulsation on same spot followed by move- } \\
\text { ment to next spot }\end{array}$ & $2 \min$ \\
\hline \multirow[t]{2}{*}{ Lower thigh circumferential } & Stationary & $50-150$ & $2.0 s / 50 \%$ & $\begin{array}{l}\text { 1. Step: } 3-5 \text { pulsation on the same spot fol- } \\
\text { lowed by movement to the next spot }\end{array}$ & $4 \min$ \\
\hline & Sliding & $50-150$ & $2.0 \mathrm{~s} / 50 \%$ & 2. Step: direction distal to proximal & $2 \min$ \\
\hline Foot dorsal and plantar & Stationary & $50-150$ & $2.0 s / 50 \%$ & $\begin{array}{l}\text { 3-5 pulsation on the same spot followed by } \\
\text { movement to the next spot }\end{array}$ & $2 \min$ \\
\hline Entire lower limb & Sliding & $50-150$ & $2.0 s / 50 \%$ & Direction distal to proximal, repeated & $5 \mathrm{~min}$ \\
\hline Inguinal area of the injured side & Stationary & $50-150$ & $2.0 s / 50 \%$ & $\begin{array}{l}3-5 \text { pulsation on the same spot followed by } \\
\text { movement to the next spot }\end{array}$ & $1 \mathrm{~min}$ \\
\hline Supraclavicular fossa region & Stationary & $50-80$ & $2.0 s / 50 \%$ & $3-5$ pulsations & $1 \mathrm{~min}$ \\
\hline
\end{tabular}

Stationary technology: Decompression with pulsation or continuous pulsation is achieved by aa vertical pull on the tissue. The treatment cup is held at the same position for 3-5 pulsations before being moved to the next treatment area. Both areas overlap by about one third

Sliding technique: Decompression is achieved with pulsation or continuous adjustment of additional frequency changes to stimulate flow from the edematous tissue into the lymphatic system. The treatment cup is carefully slid over the skin, and a commonly used disinfectant will be applied to improve gliding

Work-to-rest ratio: The time of negative pressure application relative to the recovery time, i.e., length of the interval without negative pressure application 


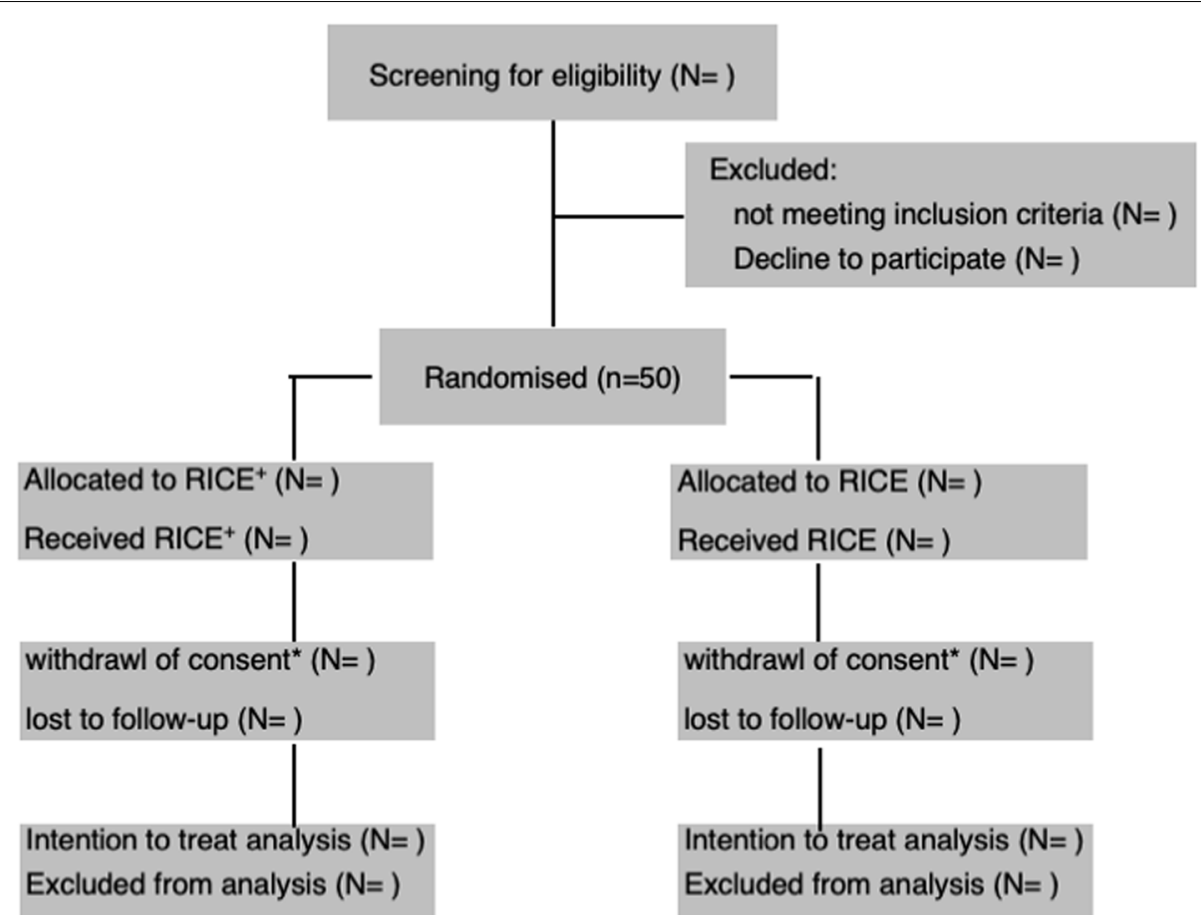

Fig. 1 Study overview * reasons for withdrawl of consent and the number of drop-outs for evaluation of the primary and secondary endopoints are recorded.m

Table 2 Time schedule of the study examinations

\begin{tabular}{lllllll}
\hline Screening & $\begin{array}{l}\text { The day } \\
\text { before } \\
\text { surgery }\end{array}$ & $\begin{array}{l}\text { Postoperative period starting day } 2 \\
\begin{array}{l}\text { Daily until Every 2nd day Discharge } \\
\text { discharge }\end{array}\end{array}$ & $\begin{array}{l}\text { Follow-up } \\
\text { (weeks 2, 4, 6) }\end{array}$ & $\begin{array}{l}\text { Final visit } \\
(\text { week } \\
12)\end{array}$ \\
\hline
\end{tabular}

Inclusion/exclusion criteria

Informed consent

Demographic and medical history

Food Frequency Questionnaire ${ }^{17}$

Baseline laboratory test ${ }^{b}$

Serum/urine sampling ${ }^{c}$

Scoring of BMD ${ }^{d}$

Ankle swelling

Demand for analgesics

Pain perception (NAS)

Range of motion

Walking abilities

\begin{tabular}{|c|c|c|c|c|c|}
\hline$x$ & & & & $x^{a}$ & $x$ \\
\hline$x$ & & & $x$ & & $x$ \\
\hline$x$ & & $x$ & $x$ & $x$ & $x$ \\
\hline$x$ & & & $x$ & & $x$ \\
\hline$x$ & $x$ & & $x$ & $x$ & $x$ \\
\hline$x$ & $x$ & & $x$ & $x$ & $x$ \\
\hline$x$ & $x$ & & $x$ & $x$ & $x$ \\
\hline & & & $x$ & $x$ & $x$ \\
\hline & & & $x$ & $x$ & $x$ \\
\hline
\end{tabular}

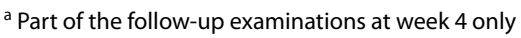

${ }^{b}$ Routinely performed serum analysis (thyroid hormones, renal and liver function, clotting test, blood cell count) plus the determination of parathyroid hormone, 25-hydroxy vitamin $D$, total and ionized serum calcium, and phosphate

' Determination of $\delta^{44 / 42} \mathrm{Ca}$ (serum and urine), fetuin-A (serum), and FGF-23 (serum)

${ }^{\mathrm{d}}$ Bone mineral density will be scored as normal, osteopenic, or osteoporotic by utilization of quantitative pulse echography (Bindex ${ }^{\circledR}$, Bone Index Finland Ltd., Kuopio, Finland)

Artec Studio, Luxembourg, Luxembourg) will be used to determine the volume of both ankles. To account for the interindividual variability of the ankle volume, per patient, the volume of the fractured ankle will be normalized to the one determined at the healthy site. The scan will cover an area ranging from the planta pedis up 
to one-third of the lower leg. The latter is defined as the distance between the medial knee joint space and the medial ankle. The upper border of the area to be scanned will be marked with permanent felt-tip pens. Proprietary software of the scanner (Artec studio V15, Artec3D, Luxembourg, Luxembourg) will be used to quantify ankle volumes. To minimize the effects of wound dressing, in all patients, a sterile and transparent film dressing (OPSITE $^{\circledR}$ Post-OP visible, Smith \& Nephew Woundcare, Hamburg, Germany) will be applied on the 2nd postoperative day .

\section{Requirement of analgesics and perception of pain during postoperative recovery in the hospital}

Secondary objectives are the need for analgesics (type and amount of the prescribed ones and those beyond) during post-operative recovery and the individual perception of pain. The information will be gathered by chart review, interview, and utilization of a numeric analog scale (NAS), respectively. The latter is scaled from zero (no pain at all) to ten (maximum pain) and the patient is asked to rank the perceived pain accordingly.

\section{Recurrence of mobility during postoperative recovery \\ and follow-up}

Clinically common goniometers will be used to gain knowledge on the mobility (ROM) of the affected and contralateral ankle joint (dorsi- and plantarflexion) at the time of discharge from the hospital and during follow-up according to the neutral zero method.

These investigations are paralleled by an assessment of the functional outcome, i.e., the walking abilities. For this purpose, pressure-sensitive insoles (loadsol ${ }^{\circledR}$ system, novel $\mathrm{GmbH}$, Munich, Germany) providing timeresolved information on normal ground reaction forces will be used. The patients are provided with the system at the time of discharge and during follow-up visits and will use it with or without assistive devices, as appropriate. Every session will start with a familiarization period followed by a recording of time-resolved normal ground reaction forces during $3 \mathrm{~min}$ straight level walking at a self-selected speed. This approach will provide information on functional recovery, i.e., cadence, gait velocity, and the factor of imbalance as a surrogate marker for recurrence of gait symmetry during fracture healing.

\section{Ca accrual to the bone during fracture healing}

Recently, the naturally occurring stable (non-radioactive) $\mathrm{Ca}$ isotopes ${ }^{44} \mathrm{Ca}$ and ${ }^{42} \mathrm{Ca}$ have been established as markers of bone mineral balance. Both isotopes are provided by and absorbed from the diet and the rate of sequestering into different body compartments is intimately linked to the atomic mass. Thus, chemical transport reactions result in an enrichment of ${ }^{42} \mathrm{Ca}$ in the respective compartment of the body, while the isotopically heavier ${ }^{44} \mathrm{Ca}$ is excreted [16, 25-27]. Consequently, the $\delta^{44 / 42} \mathrm{Ca}_{\text {serum }}$ ratio reflects bone mineral balance, i.e., the ratio is higher under conditions of mineral accrual by the skeleton compared to a situation when bone resorption exceeds bone formation. The same holds true for the isotope ratios in urine and feces [15]. To monitor accrual of Ca during fracture healing, patients are asked to provide serum and urine samples on a voluntary basis the morning before surgical fixation of the fracture, at least once during postoperative recovery, at time of discharge from the hospital, and at the time of the follow-up visits. All samples will be taken after overnight fasting and will be stored at -80 ${ }^{\circ} \mathrm{C}$ until the time of analysis, and patients will be asked to record a food frequency questionnaire before the followup visits [28].

\section{Scoring of bone mineral density}

Quantitative pulse echography (Bindex ${ }^{\circledR}$, Bone Index Finland, Ltd., Kuopio, Finland) is used to assess bone mineral density the day before surgery, at the time of discharge, and the final visit. In particular, the cortical thickness of the healthy tibia is measured and translated into an estimate of bone mineral density (i.e., healthy, osteopenic, and osteoporotic bone) via the in-build proprietary algorithm $[24,29]$.

\section{Adverse events reporting and data safety monitoring}

This is a single-center evaluator blinded randomized controlled pilot study, and the device-based application of negative pressure therapy is deemed to be of rather low risk. The same holds true for the proposed outcome measures, i.e., chart review, questionnaires, and touchless 3D optical scanning of the ankle and lower leg. However, all complications (e.g., wound-healing problems, infections) are to be recorded, and participants will be encouraged to report any discomfort related to either therapy or outcome measures. Discontinuation or modification of the treatment will be an individual decision of the responsible physician. There will be no special criterion for stopping the trial except for severe postoperative complications making a surgical reintervention necessary.

\section{Data collection, management, and statistical analysis}

Clinical and anthropometric data including a history of disease, time to surgery, current medication, staged or single-step surgery, comorbidities, and the results of routine assessments (clinical chemistry, imaging) at baseline will be gathered by chart review and interview. Furthermore, postoperative complications (wound healing problems, non-union, infections) are recorded in both 
treatment groups. At the time of enrollment, patients will receive a unique identification code (ID), and all documents and hard copies generated for the purpose of this trial will be linked to this identifier. The underlying key will be stored in a password-protected file accessible only to the principal investigators (DCF, TM). Of note, the evaluator will be unblinded only after the last patient has finalized the study examinations. Regardless of this, access to the data will be limited to the researchers involved in this trial.

Data will be analyzed using the SPSS statistical package 26.0 (SPSS Inc., Chicago, IL) and Sigma Plot V10 (Systat Software GmbH, Erkrath, Germany) for graphical presentation. The normal distribution of continuous variables will be evaluated by the Kolmogorov-Smirnov test, descriptive summary measures will be calculated. Categorical variables are summarized as numbers and percentages. For comparison of the categorical variables, the chi-square test or Fisher's exact test will be used, as appropriate. Repeated measure analysis will allow for longitudinal examination of the treatment effects and differences between the study groups. Data from all randomized participants will be included (intent-to-treat analysis). No missing data imputation will be performed, and in view of the rather small number of participants per treatment arm, neither subgroup or adjusted analyses are planned. During the study, patients and personnel are encouraged to mention all problems related to the study investigations and especially to the acceptance of the contact-less 3D optical scanning procedure. At the time of discharge, patients randomized to $\mathrm{RICE}^{+}$will be asked by the one in charge for the application of the device-based negative pressure therapy to rate this additional treatment on a scale ranging from 1 (very good) to 5 (no effect). Proceeding to the main trial will be deemed feasible if (a) at least two-thirds of the patients allocated to $\mathrm{RICE}^{+}$will retrospectively judge this additional treatment positive and (b) at least two-thirds of all patients accept the repetitive contact-less 3D optical scanning procedure.

\section{Discussion}

The study is designed to assess the effects of the classical RICE concept and the additional application of a devicebased negative pressure therapy $\left(\mathrm{RICE}^{+}\right)$with respect to the resorption of lymphedema related to the surgical fixation of an isolated ankle fracture. Although standardization of the components of RICE is hard to achieve even in a hospital setting, we record the number of ice packages per day not only as a marker of the individual preference for cooling but as a surrogate marker of adherence to the baseline therapy, as well. To objectively assess the effects of either therapeutic approach, we decided to perform touchless 3D optical scanning as this turned out to be a highly reliable technique for quantifying the volume of the foot and ankle region [14]. Given the multiple implications of ankle swelling with respect to pain, complications, mobility, and outcome, we selected a rather broad panel of outcome measures covering a 12-week postoperative interval. Although this approach might be prone to any bias related to the RICE concept and/or to the individual care after discharge from the hospital, it will certainly provide data on the immediate effects of RICE vs $\mathrm{RICE}^{+}$. The blinding of the evaluator and even the staff involved in surgery and postoperative care and the fact that the person in charge for the device-based application of negative pressure therapy will show up anyway are expected to minimize the risk of a bias in standard care. Further, the dynamics of the ratio of naturally occurring calcium isotopes in relation to the postoperative development of lymphedema, the manifestation of eventual postoperative complications as infection or non-union, and bone mineral density will permit insight into the mechanisms of interaction between perioperative swelling and uneventful bone remineralization or prolonged demineralization in case of complications in the postoperative period. In summary, the results of the proposed pilot study will enable us to decide whether it is worth comparing the effects of RICE and $\mathrm{RICE}^{+}$in a sufficiently powered multicenter trial and which of the outcome markers are best suited for this purpose. Without saying, this decision will consider the feedback of patients on either therapeutic approach as well as comments from the staff.

\section{Ethics and dissemination}

The protocol was approved by the institutional Ethics Committee (Rostock University Medical Center, Rostock, Germany) in accordance with the Declaration of Helsinki (approval number: A 2020-0092). The results of this study will be actively disseminated through scientific publications and conference presentations.

\section{Trial registration}

DRKS Identifier 00023739 version 1, posted on December 3, 2020. Recruitment is scheduled from June 2021 to June 2022.

\section{Protocol amendments}

Any changes to the protocol will be presented for approval to the university's ethics committee. Subsequently, the revised version of the protocol will be deposited at the DRKS - German Clinical Trials Register (https://www.dimdi.de/dynamic/de/weitere-fachdienste/deutsches-register-klinischer-studien/studienregistri erung/). 


\section{Collection of biological specimens}

This trial involves the voluntary provision of blood and urine samples for additional biochemical analysis of markers related to bone metabolism and mineralization.

\section{Acknowledgements}

We appreciate our participants for their interest in the research and enthusiasm to stimulate the resorption of postoperative swelling by physical therapy.

\section{Authors' contributions}

TM, KD, and DCF: study conception and execution, protocol design, obtained study funding, and manuscript writing. AG and AS: participant recruitment, data collection, and manuscript writing. AE: analysis of $\delta^{44 / 42} \mathrm{Ca}$ ratio. LV: analysis of food questionnaire. No professional writers have been involved. All named authors adhere to the authorship guidelines of trials and have agreed for publication. The authors read and approved the final manuscript.

\section{Funding}

Open Access funding enabled and organized by Projekt DEAL. This trial is sponsored by LymphaTouch Inc., Helsinki, who supplied 2 devices free of charge for the study period. The funder has no role in the study design, collection, analysis and interpretation of the data, or preparation of the manuscript.

\section{Availability of data and materials}

No datasets were used or analyzed in this manuscript. Details about the procedures and information materials handed to the participants will be provided on reasonable request.

\section{Declarations}

\section{Ethics approval and consent to participate}

The study was approved by the institutional Ethics Committee (Rostock University Medical Center, Rostock, Germany) in accordance with the Declaration of Helsinki (approval number: A 2020-0092). All participants read and sign an informed consent prior to participation.

\section{Consent for publication}

Not applicable.

\section{Competing interests}

$D C F, A S, A G, A E$, LV, and TM declare that they have no competing interests. KD declares that before this study was planned, he was a medical adviser for 1 year (2019) for LymphaTouch ${ }^{\circledR}$ to initiate other RCTs.

\section{Author details \\ 1 Department of Pediatrics, Rostock University Medical Center, Ernst-Heyde- mann-Str. 8, 18057 Rostock, Germany. ${ }^{2}$ Department of Traumatology, Hand and Reconstructive Surgery, Rostock University Medical Center, Rostock, Germany. ${ }^{3}$ Department of Trauma Surgery, Orthopaedics and Plastic Surgery, University Medicine Göttingen, Georg-August-University, Göttingen, Germany. ${ }^{4}$ GEOMAR Helmholtz Center for Ocean Research Kiel, Kiel, Germany. ${ }^{5}$ Depart- ment of Agriculture and Food Sciences, Neubrandenburg Institute for Evi- dence-Based Dietetics (NIED), University of Applied Sciences Neubranden- burg, Neubrandenburg, Germany.}

Received: 16 February 2021 Accepted: 1 November 2021 Published online: 12 November 2021

\section{References}

1. Atesok K, Finkelstein J, Khoury A, Peyser A, Weil Y, Liebergall M, et al. The use of intraoperative three-dimensional imaging (ISO-C-3D) in fixation of intraarticular fractures. Injury. 2007;38(10):1163-9.

2. Rammelt S, Zwipp H, Grass R. Ankle fractures: operative techniques. Unfallchirurg. 2008;111(6):439-47.

3. Court-Brown CM, Caesar B. Epidemiology of adult fractures: a review. Injury. 2006;37(8):691-7.
4. Kannus P, Palvanen M, Niemi S, Parkkari J, Jarvinen M. Increasing number and incidence of low-trauma ankle fractures in elderly people: Finnish statistics during 1970-2000 and projections for the future. Bone. 2002;31(3):430-3.

5. Preston NJ, Seers K, Mortimer PS: Physical therapies for reducing and controlling lymphoedema of the limbs. Cochrane Database Syst Rev 2004:Art. No. CD003141. https://doi.org/10.1002/14651858.CD003141. pub2.

6. Vairo GL, Miller SJ, McBrier NM, Buckley WE. Systematic review of efficacy for manual lymphatic drainage techniques in sports medicine and rehabilitation: an evidence-based practice approach. J Man Manip Ther. 2009;17(3):e80-9.

7. Majewski-Schrage T, Snyder K. The effectiveness of manual lymphatic drainage in patients with orthopedic injuries. J Sport Rehabil. 2016;25(1):91-7.

8. Saul D, Fischer AC, Lehmann W, Dresing K. Reduction of postoperative swelling with a negative pressure treatment-a prospective study. J Orthop Surg (Hong Kong). 2020;28(2). https://doi.org/10.1177/23094 99020929166.

9. Ebert JR, Joss B, Jardine B, Wood DJ. Randomized trial investigating the efficacy of manual lymphatic drainage to improve early outcome after total knee arthroplasty. Arch Phys Med Rehabil. 2013;94(11):2103-11.

10. Pichonnaz C, Bassin JP, Lecureux E, Christe G, Currat D, Aminian K, et al. Effect of manual lymphatic drainage after total knee arthroplasty: a randomized controlled trial. Arch Phys Med Rehabil. 2016;97(5):674-82.

11. Kessler T, de Bruin E, Brunner F, Vienne P, Kissling R. Effect of manual lymph drainage after hindfoot operations. Physiother Res Int. 2003;8(2):101-10.

12. Klein I, Tidhar D, Kalichman L. Lymphatic treatments after orthopedic surgery or injury: a systematic review. J Bodyw Mov Ther. 2020;24(4):109-17.

13. Dresing K, Fischer AC, Lehmann W, Saul D, Spering C. Perioperative and posttraumatic anti-edematous decongestive device-based negative pressure treatment for anti-edematous swelling treatment of the lower extremity - a prospective quality study. Int J Burns Trauma. 2021;11(3):145-55.

14. Hofmann B, Konopka K, Fischer D-C, Kundt G, Martin H, Mittlmeier T: 3D optical scanning as an objective and reliable tool for volumetry of the foot and ankle region. Foot Ankle Surg 2021, online ahead of print; Accession Number: 33745795. https://doi.org/10.1016/j.fas.2021.03. 009.

15. Shroff R, Fewtrell M, Heuser A, Kolevica A, Lalayiannis A, McAlister $L$, et al. Naturally occurring stable calcium isotope ratios in body compartments provide a novel biomarker of bone mineral balance in children and young adults. J Bone Miner Res. 2021;36(1):133-42.

16. Eisenhauer A, Muller M, Heuser A, Kolevica A, Gluer CC, Both M, et al. Calcium isotope ratios in blood and urine: a new biomarker for the diagnosis of osteoporosis. Bone Rep. 2019;10:100200.

17. [http://www.jerrydallal.com/random/randomize.htm]

18. Sim J, Lewis $M$. The size of a pilot study for a clinical trial should be calculated in relation to considerations of precision and efficiency. J Clin Epidemiol. 2012;65(3):301-8.

19. Julious SA. Sample size of 12 per group rule of thumb for a pilot study. Pharm Stat. 2005;4(4 \%@ 1539-1604):287-91.

20. Viechtbauer W, Smits L, Kotz D, Bude L, Spigt M, Serroyen J, et al. A simple formula for the calculation of sample size in pilot studies. J Clin Epidemiol. 2015;68(11):1375-9.

21. Whitehead AL, Julious SA, Cooper CL, Campbell MJ. Estimating the sample size for a pilot randomised trial to minimise the overall trial sample size for the external pilot and main trial for a continuous outcome variable. Stat Methods Med Res. 2016;25(3):1057-73.

22. Földi $E$, Földi $M$, Weissleder H. Conservative treatment of lymphoedema of the limbs. Angiology. 1985;36(3):171-80.

23. Wittlinger $D$, Wittlinger $H$, Wittlinger $A$. Dr. Vodder's manual lymph drainage. A practical guide. New York, Stuttgart: Thieme Publishers; 2018.

24. Behrens M, Felser S, Mau-Moeller A, Weippert M, Pollex J, Skripitz R, et al. The Binde ${ }^{\circledR}$ ultrasound device: reliability of cortical bone thickness measures and their relationship to regional bone mineral density. Physiol Meas. 2016;37(9):1528-40. 
25. Heuser A, Eisenhauer A. A pilot study on the use of natural calcium isotope $(44 \mathrm{Ca} / 40 \mathrm{Ca})$ fractionation in urine as a proxy for the human body calcium balance. Bone. 2010;46(4):889-96.

26. Morgan JL, Skulan JL, Gordon GW, Romaniello SJ, Smith SM, Anbar AD. Rapidly assessing changes in bone mineral balance using natural stable calcium isotopes. Proc Natl Acad Sci U S A. 2012;109(25):9989-94.

27. Skulan J, Bullen T, Anbar AD, Puzas JE, Shackelford L, LeBlanc A, et al. Natural calcium isotopic composition of urine as a marker of bone mineral balance. Clin Chem. 2007;53(6):1155-8.

28. Haftenberger M, Heuer T, Heidemann C, Kube F, Krems C, Mensink GB. Relative validation of a food frequency questionnaire for national health and nutrition monitoring. Nutr J. 2010;9:36.
29. Lewiecki EM. Pulse-echo ultrasound identifies Caucasian and Hispanic women at risk for osteoporosis. J Clin Densitom. 2020;24(2):175-82.

\section{Publisher's Note}

Springer Nature remains neutral with regard to jurisdictional claims in published maps and institutional affiliations.
Ready to submit your research? Choose BMC and benefit from:

- fast, convenient online submission

- thorough peer review by experienced researchers in your field

- rapid publication on acceptance

- support for research data, including large and complex data types

- gold Open Access which fosters wider collaboration and increased citations

- maximum visibility for your research: over 100M website views per year

At BMC, research is always in progress.

Learn more biomedcentral.com/submissions 